\title{
Sensor Applications Using Sol-Gel Technique
}

\author{
Nidhin Francis ${ }^{1}$, Ponni Balakrishnan ${ }^{2}$, Siby Mathew ${ }^{3}$ \\ Department of Physics, Sacred Heart College Thevara, India ${ }^{1,2,3}$
}

\begin{abstract}
We prepared sol-gel samples by hydrolysis of tetraethyl orthosilicate (TEOS). FTIR studies are done on the samples heated at different temperatures to confirm the glassy network. Porosity studies confirmed the pore size of around $22 \mathrm{~nm}$. Acid /Alkali indicators like methyl orange, phenolphthalein and universal indicator doped sol-gel glasses are prepared. These glasses can be used as acid/alkali reversible solid indicators. V-I characteristics are drawn for these glasses using a diode laser photo detector set up. These glasses find application as a solid-pH sensor. Samples are also prepared by doping them with suitable chemicals which find application as a sensor for industrial chemical leakage.
\end{abstract}

Key words: sol-gel process, industrial chemical sensor, $\mathrm{pH}$ sensor, porosity studies.

\section{INTRODUCTION}

Sol-gel processing is a low temperature method which is used for the fabrication of inorganic or composite organic materials such as glasses, thin films, ceramics or powdersof high homogeneity and purity [1]. It is based on the mixing of liquid reactants on molecular scale and solidification of solution into a porous amorphous oxide gel. Sol-gel process for the synthesis of glass and ceramics has attracted increasing scientific and technological interest.

\section{Structural studies of sol-gel silica glass}

In this paper we describe about the structural modification during the gel to glass transition. Structural properties of sol-gel glass such as characteristics of porous width and FTIR spectra of sol-gel glasses have important role in determining the glassy network. We have prepared sol-gel glass samples at room temperature, $100^{\circ} \mathrm{C}, 200^{\circ} \mathrm{C}, 500^{\circ} \mathrm{C}$ and $800^{\circ} \mathrm{C}$. The FTIR spectrums of these glass samples were taken. The hydrolysis and polymerization of the prepared glass sample have investigated. The hydrolysis of tetraethyl orthosilicate (TEOS) with $\mathrm{Si}-\mathrm{OH}$ groups which react with other $\mathrm{Si}-\mathrm{OH}$ groups through polycondensation, gives us a three-dimensional silica network.

Silica sol-gel glasses are porous materials whose pore size can be tailored effectively. On comparison to size of the piece material considered the pores must be extremely small.[2]. The porous glass can be produced in high quality and with pore sizes ranging from $1 \mathrm{~nm}$ up to millimetre order. Incorporation of nanomaterials in the body of sol-gel glasses opens a wide field of applications. Most of the porous materials do not have uniform pores. The pore size distribution is also an important property. Moreover the narrow pore size distribution, i.e., uniform pore size is required for filters and bioreactor beds.

\section{Study of pH indicator in sol-gel silica glass}

Recently, it has been proposed that the determination of $\mathrm{pH}$ has a wide range importance in the medical, environmental and biotechnological fields [3].pH is defined as the negative logarithm to base 10 of the activity of the hydrogen ion [4]. $\mathrm{pH}$ indicator is a halochromic material added to a solution that changes the $\mathrm{pH}$ of the solution. Because of subjective determination of colour, $\mathrm{pH}$ indicators are susceptible to imprecise readings. We have prepared indicator such as phenolphthalein, methyl orange and universal indicator doped sol-gel glass samples at room temperature. Also we have identified that the indicator doped glass shows reversible characteristics. By using a laser diode-photo detector set up we have measuredthe variation of current with respect to voltage, which is due to the high variation of colour in acidic and alkali medium. The change in colour is due to the change in $\mathrm{pH}$ values of the indicator.

\section{Industrial Chemical Leakage sensor}

The sol-gel derived chemical sensors have blossomed since the mid-1980's. Sol-gel derived matrices as host provide better stability, flexibility, optical transparency and permeability[5-8].However, sensor technology is a multidisciplinary field and more and more scientists are now crossing discipline boundaries thus new research groups are being set up [9].Chemical sensors are developed for a large variety of applications such as industrial hygiene, process control, clinical diagnostics and more recently home land security. This paper summarizes the effort that we have made on implementing the sol-gel technology in sensor applications. We proposed that sol-gel glass doped with certain chemicals, act as a sensor to detect the industrial chemical leakage. Because of the ease of fabrication and design flexibility, studies in optical chemical sensor are an attracting research field [10].

\section{EXPERIMENTAL}

\section{Preparation of sol-gel silica glass samples}

Sol-gel silica glasses were prepared [11] by the hydrolysis of tetraethyl orthosilicate (TEOS). Mix $6 \mathrm{ml}$ of tetraethyl orthosilicate (TEOS) with $2 \mathrm{ml}$ of water $\left(\mathrm{H}_{2} \mathrm{O}\right) \& 2 \mathrm{ml}$ of ethanol $\left(\mathrm{C}_{2} \mathrm{H}_{5} \mathrm{OH}\right)$ and the mixture was stirred magnetically. After preparation, samples were dried at room temperature for 5 days. Samples heated at different temperatures using hot air oven. The FTIR spectra were taken using the Shi madzu FTIR spectrometer.

\section{Preparation of indicator doped glass samples}

Mix $6 \mathrm{ml}$ of tetraethyl orthosilicate (TEOS) with $0.5 \mathrm{ml}$ of methyl orange, $2 \mathrm{ml}$ of water $(\mathrm{H} 2 \mathrm{O}) \& 2 \mathrm{ml}$ of ethanol $\left(\mathrm{C}_{2} \mathrm{H}_{5} \mathrm{OH}\right)$. After stirring the complex gel using a magnetic stirrer, they kept at room temperature, dried for 5 days. Thus methyl orange doped glass samples were prepared. 
INTERNATIONAL JOURNAL OF INNOVATIVE RESEARCH IN ELECTRICAL, ELECTRONICS, INSTRUMENTATION AND CONTROL ENGINEERING Vol. 3, Issue 12, December 2015

Continue the process by replacing phenolphthalein and universal indicator. Set up a circuit as shown in figure 1 .

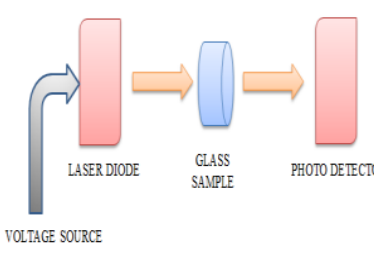

(a)

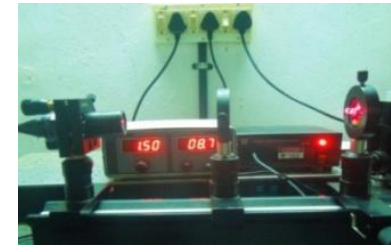

(b)
Figure 1: (a) schematic diagra9m of $\mathrm{pH}$ sensor set up (b) original set up of $\mathrm{pH}$ sensor

Preparation of chemical doped glass samples for the industrial chemical leakage sensor

In order to prepare transparent silver nitrate doped glass sample, first mix $6 \mathrm{ml}$ of tetraethyl orthosilicate (TEOS) with $1 \mathrm{ml}$ of silver nitrate solution, $2 \mathrm{ml}$ of water $\left(\mathrm{H}_{2} \mathrm{O}\right)$ \& $2 \mathrm{ml}$ of ethanol $\left(\mathrm{C}_{2} \mathrm{H}_{5} \mathrm{OH}\right)$ and stir the complex gel using a magnetic stirrer. They were kept under room temperature, dried for 5 days. Thus the silver nitrate doped glass samples prepared. Same process is repeated for the preparation of barium chloride and copper sulphate. The leakage can be identified by the help of an alarm circuit (shown in figure 2) that can sense the light beams falls on it. The basic idea is that when certain chemical falls on the prepared sample, the glass loses its transparency and turns into opaque. The so prepared sample was kept between a laser source and the alarm circuit as shown in the figure 2(a). When few drops of chemical (example-hydrochloric acid) fall on the sample the transparent glass sample turns opaque. This sudden change will switch on the alarm circuit.

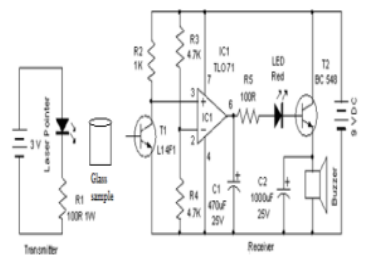

(a)

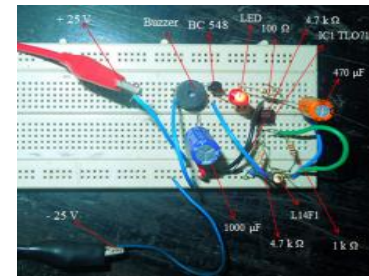

(b)
Figure 2: (a) schematic diagram of chemical sensor set up (b) original set up of chemical sensor using photo detector

\section{RESULT AND DISCUSSION}

\section{FTIR spectrum analysis}

In summary, the gel at room temperature shows a wide bands in the IR spectrum characteristic of adsorbed water and $\mathrm{Si}-\mathrm{OH}$ stretching vibration(bands at $3000-3800 \mathrm{~cm}^{-}$ ${ }^{1}$ and $1645 \mathrm{~cm}^{-1}$ ). It is observed that the intensity of these bands show substantial decrease above $200{ }^{\circ} \mathrm{C}$ and have negligible intensity in the high temperature annealed samples. These results confirm that a substantial portion of the water and residual organic molecules in dried silica gels have been removed above this temperature.

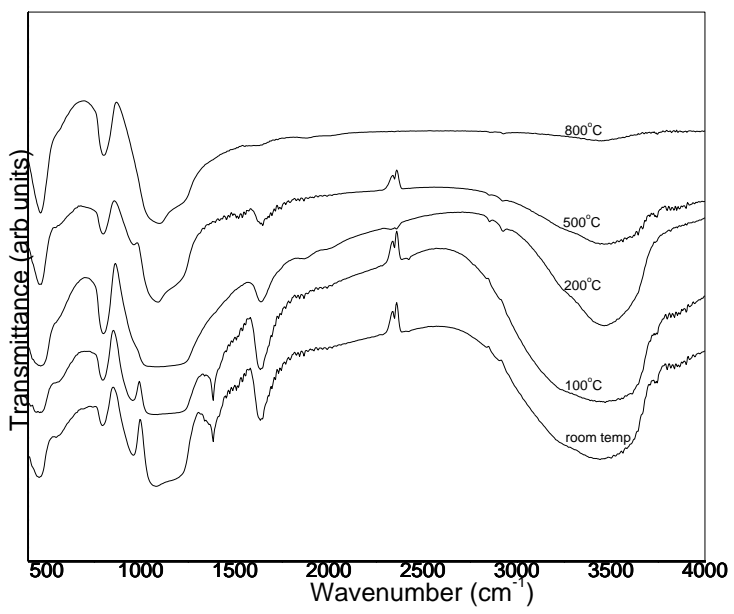

Figure 3: FTIR spectrum of sol-gel glass at different temperature

\begin{tabular}{|c|c|}
\hline IR peaks $\left(\mathrm{cm}^{-1}\right)$ & Assignments \\
\hline $3800-3000$ & $\mathrm{~V}_{\mathrm{OH}}$ of absorbed water \\
\hline 1635 & $\begin{array}{l}\mathrm{V}_{\mathrm{OH}} \text { of water absorbed on } \\
\text { to } \mathrm{Si}-\mathrm{OH} \text { with hydrogen } \\
\text { bonding }\end{array}$ \\
\hline 1385 & $\delta \mathrm{CH}_{3}$ Symmetric bend \\
\hline 1180 & Si-O-Si Symmetric stretch \\
\hline 1085 & $\begin{array}{l}\text { Si-O-Si Anti-symmetric } \\
\text { stretch }\end{array}$ \\
\hline 960 & $\begin{array}{l}\text { Si-OH Anti symmetric } \\
\text { stretch }\end{array}$ \\
\hline 798 & O-Si-O Bend \\
\hline 460 & Si-O-Si Bend \\
\hline
\end{tabular}

Table 1: FTIR band assignments of sol-gel glass at different temperature

\section{Porosity studies:}

The interpretation of adsorption-desorption isotherms provides information on the texture of the adsorbent. The main parameters which can be measured are surface area, pore volume and pore size. We have investigated using single point estimation, t-Plot model, Langmuir model, BET model and BJH method [12].

The following tables (table 2-4) show their characteristics at room temperature.

\section{Surface area}

\begin{tabular}{|c|c|}
\hline Method & Surface $\operatorname{area}\left(\mathrm{m}^{2} / \mathrm{g}\right)$ \\
\hline $\begin{array}{c}\text { Single point surface area at } \\
\mathrm{p} / \mathrm{p}^{\mathrm{o}}=0.313019540\end{array}$ & 658.9452 \\
\hline BET surface area & 667.2386 \\
\hline Langmuir surface area & 104.04309 \\
\hline t-Plot & $\begin{array}{c}\text { Micropore: } 146.3620 \\
\text { External: } 520.8765\end{array}$ \\
\hline $\begin{array}{c}\text { BJH adsorption (cumulative } \\
\text { surface area of pores between } \\
17 \mathrm{~nm} \text { and 3000 nm width) }\end{array}$ & 336.1924 \\
\hline $\begin{array}{c}\text { BJH desorption (cumulative } \\
\text { surface area of pores between } \\
17 \mathrm{~nm} \text { and 3000 nm width) }\end{array}$ & 358.5095 \\
\hline
\end{tabular}

Table 2: Estimation of surface area 
INTERNATIONAL JOURNAL OF INNOVATIVE RESEARCH IN ELECTRICAL, ELECTRONICS, INSTRUMENTATION AND CONTROL ENGINEERING Vol. 3, Issue 12, December 2015

\section{Pore volume}

\begin{tabular}{|c|c|}
\hline Method & Pore volume $\left(\mathrm{cm}^{3} / \mathrm{g}\right)$ \\
\hline $\begin{array}{c}\text { Single point adsorption (total } \\
\text { pore volume of pore less } \\
\text { than1231.755 nm width at } \\
\left.\mathrm{p} / \mathrm{p}^{\circ}=0.984173850\right)\end{array}$ & 0.362509 \\
\hline t-Plot & $\begin{array}{c}\text { (micro pore) } \\
0.085923\end{array}$ \\
\hline $\begin{array}{c}\text { BJH adsorption (cumulative } \\
\text { surface area of pores between } \\
17 \mathrm{~nm} \text { and 3000 nm width) }\end{array}$ & 0.185024 \\
\hline $\begin{array}{c}\text { BJH desorption (cumulative } \\
\text { surface area of pores between } \\
17 \mathrm{~nm} \text { and 3000 nm width) }\end{array}$ & 0.191079 \\
\hline
\end{tabular}

Table 3: Estimation of pore volume

\section{Pore size}

\begin{tabular}{|c|c|}
\hline Method & Pore size obtained (nm) \\
\hline $\begin{array}{c}\text { Adsorption average pore } \\
\text { width (4 V/A) }\end{array}$ & 21.7319 \\
\hline $\begin{array}{c}\text { BJH adsorption average } \\
\text { pore width(4 V/A) }\end{array}$ & 22.014 \\
\hline $\begin{array}{c}\text { BJH desorption average } \\
\text { pore width(4 V/A) }\end{array}$ & 21.319 \\
\hline
\end{tabular}

Table 4: Estimation of pore size

Where, p-equilibrium pressure, $\mathrm{p}^{\mathrm{o}}$ - saturated vapour pressure

The main parameters (surface area, pore volume and pore size) have been found out using six calculation methods: Langmuir model, BET model, single point method, t-Plot method, BJD adsorption and BJD desorption methods. Average pore size was found to be around $22 \mathrm{~nm}$ while pore volume and surface area was around $0.20 \mathrm{~cm}^{3} / \mathrm{g} \&$ $330 \mathrm{~m}^{2} / \mathrm{g}$. these results indicates that sol-gel glasses are in nano-regime.

\section{Reversible characteristics of indicator doped sol-gel glasses}

We have identified that at room temperature indicator doped glass shows reversible characteristics. However the performance is not long lasting. It degenerate after a couple of reactions. Phenolphthalein doped glass degenerate fastly hence it can be reused up to five times while methyl orange and universal indicator doped glass lasts its reversible property up to twelve or thirteen times. The following figures (figure 4-6) shows images of indicator doped glass in acid medium and in alkali medium.

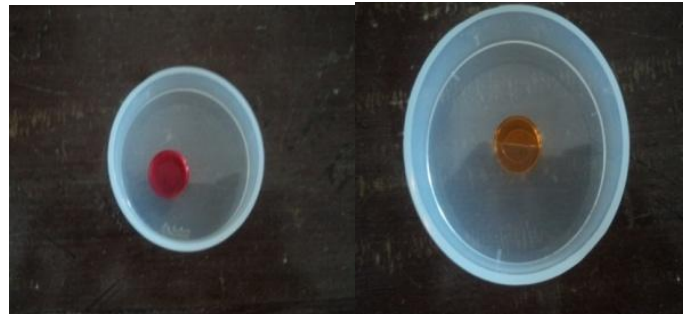

(a)

(b)

Figure 4: Methyl orange doped glass in (a) acid medium \& (b) alkali medium

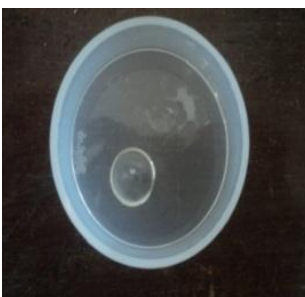

(a)

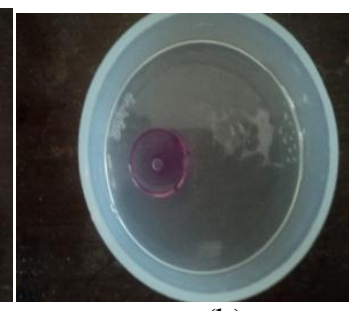

(b)
Figure 5: Phenolphthalein doped glass in (a) acid medium \& (b) alkali medium

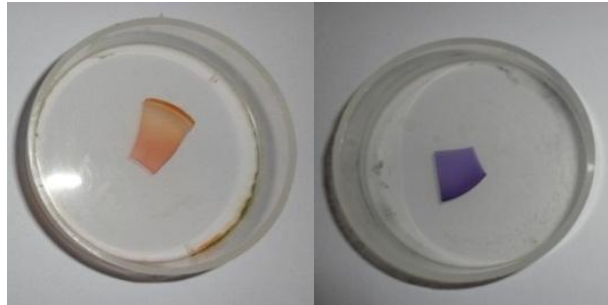

(a)

(b)

Figure 6: Universal indicator doped glass in (a) acid medium \& (b) alkali medium

\section{V-I Characteristics of indicator doped glasses}

Here we have tabulated (tables 5-7) and plotted (figure 79) the current -voltage relation of certain indicator doped sol-gel glasses.

1. Methyl orange doped glass in acid and alkali medium

\begin{tabular}{|c|c|c|}
\hline \multirow{2}{*}{$\begin{array}{c}\text { Voltage } \\
(\mathrm{V})\end{array}$} & \multicolumn{2}{|c|}{ Current (mA) } \\
\cline { 2 - 3 } & Acid Medium & Alkali Medium \\
\hline 1.5 & 12.5 & 10.2 \\
\hline 2.0 & 14.6 & 12.2 \\
\hline 2.5 & 16.6 & 14.1 \\
\hline 3.0 & 18.4 & 15.7 \\
\hline 3.5 & 20.1 & 17.2 \\
\hline 4.0 & 21.6 & 18.5 \\
\hline 4.5 & 23 & 19.7 \\
\hline 5.0 & 24.3 & 20.7 \\
\hline 5.5 & 25.5 & 21.7 \\
\hline 6.0 & 26.6 & 22.5 \\
\hline 6.5 & 27.8 & 23.2 \\
\hline
\end{tabular}

Table 5: Methyl orange doped glass in acid and alkali medium

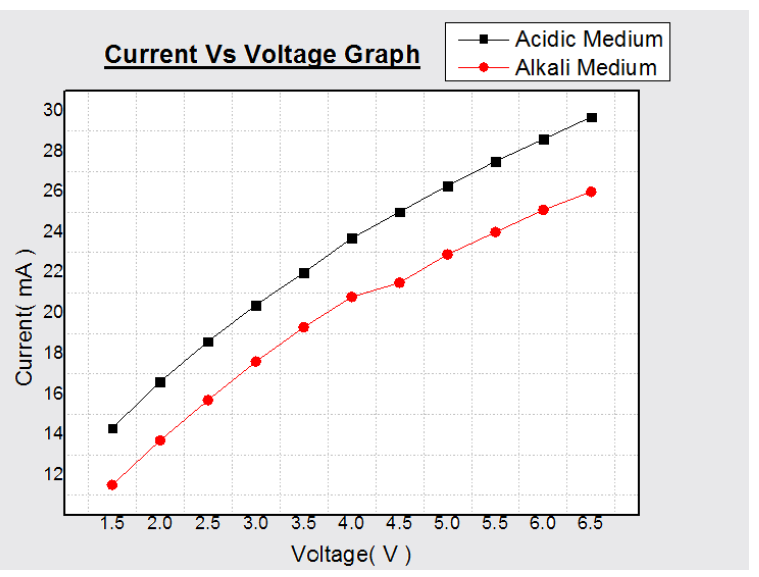

Figure 7: Current Vs Voltage graph of methyl orange doped glass sample 
INTERNATIONAL JOURNAL OF INNOVATIVE RESEARCH IN ELECTRICAL, ELECTRONICS, INSTRUMENTATION AND CONTROL ENGINEERING Vol. 3, Issue 12, December 2015

2. Phenolphthalein doped glass in acid and alkali medium

\begin{tabular}{|c|c|c|}
\hline \multirow{2}{*}{$\begin{array}{c}\text { Voltage } \\
(\mathrm{V})\end{array}$} & \multicolumn{2}{|c|}{ Current (mA) } \\
\cline { 2 - 3 } & Acid Medium & Alkali Medium \\
\hline 1.5 & 14.3 & 11.5 \\
\hline 2.0 & 16.6 & 13.7 \\
\hline 2.5 & 18.6 & 15.7 \\
\hline 3.0 & 20.4 & 17.6 \\
\hline 3.5 & 22 & 19.3 \\
\hline 4.0 & 23.7 & 20.8 \\
\hline 4.5 & 25 & 21.5 \\
\hline 5.0 & 26.3 & 22.9 \\
\hline 5.5 & 27.5 & 24 \\
\hline 6.0 & 28.6 & 25.1 \\
\hline 6.5 & 29.7 & 26 \\
\hline
\end{tabular}

Table 6: Phenolphthalein doped glass in acid and alkali medium

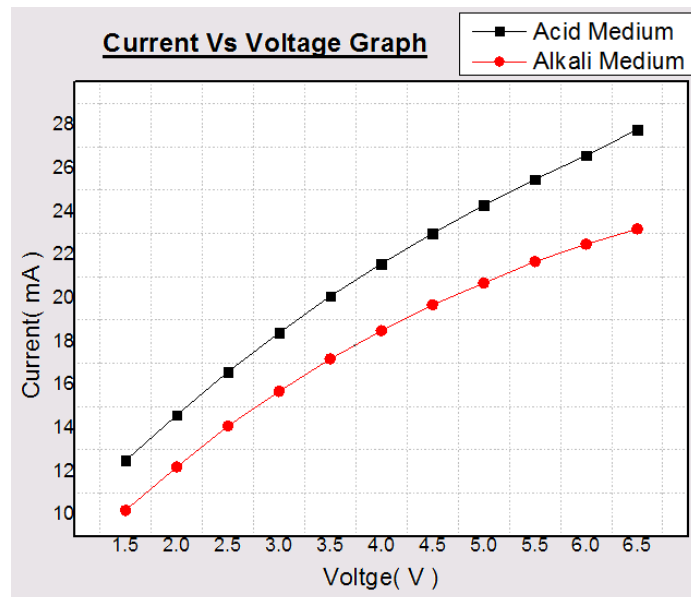

Figure 8: Current Vs Voltage graph of phenolphthalein doped glass sample

3. Universal indicator doped glass for $\mathrm{pH} 5, \mathrm{pH} 7$ and $\mathrm{pH} 10$

\begin{tabular}{|c|c|c|c|}
\hline \multirow{2}{*}{$\begin{array}{c}\text { Voltage } \\
(\mathrm{V})\end{array}$} & \multicolumn{3}{|c|}{ Current (mA) } \\
\cline { 2 - 4 } & $\mathrm{pH} 5$ & $\mathrm{pH} 7$ & $\mathrm{pH} 10$ \\
\hline 1.5 & 11.8 & 13.7 & 14.4 \\
\hline 2.0 & 13.9 & 16.1 & 16.8 \\
\hline 2.5 & 15.8 & 18.3 & 19.0 \\
\hline 3.0 & 17.6 & 20.2 & 21.0 \\
\hline 3.5 & 19.1 & 22 & 22.9 \\
\hline 4.0 & 20.6 & 23.6 & 24.3 \\
\hline 4.5 & 22 & 25 & 26.1 \\
\hline 5.0 & 23.3 & 26.3 & 27.5 \\
\hline 5.5 & 24.6 & 27.6 & 28.9 \\
\hline 6.0 & 25.6 & 28.5 & 30.9 \\
\hline 6.5 & 26.7 & 29.5 & 31.1 \\
\hline
\end{tabular}

Table 7: Universal indicator doped glass for $\mathrm{pH}$ 5, $\mathrm{pH} 7$ and $\mathrm{pH} 10$

The above diagrams shows that the current variation with voltage can be used to study the transition of indicator doped glass from acid to alkali medium. The approximate range of $\mathrm{pH}$ value can be determined because of the strong colour change of indicator doped glasses in acid and alkali medium.

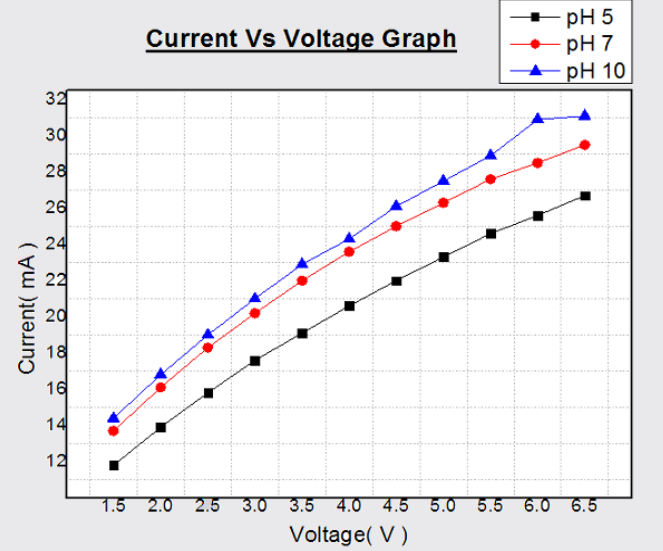

Figure 9: Current Vs Voltage graph of universal indicator doped glass sample

\section{Chemical sensor}

In this study we have identified the leakage of two chemicals one hydrochloric acid $(\mathrm{HCl})$ and the other sodium chromate $\left(\mathrm{Na}_{2} \mathrm{CrO}_{4}\right)$. We have prepared transparent sol-gel samples doped with silver nitrate $\left(\mathrm{AgNO}_{3}\right)$ solution using sol-gel technique. When few drops of hydrochloric acid $(\mathrm{HCl})$ solution falls on the sample, the sample turns opaque due to the following reaction,

$$
\mathrm{HCl}+\mathrm{AgNO}_{3} \rightarrow \mathrm{AgCl}+\mathrm{HNO}_{3}
$$

This is an ideal sensor to detect thehydrochloric acid $(\mathrm{HCl})$ leakage (figure 10).

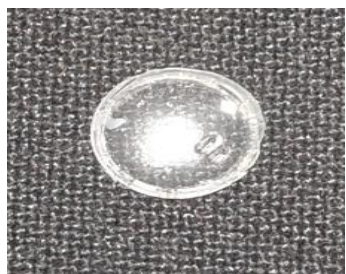

(a)

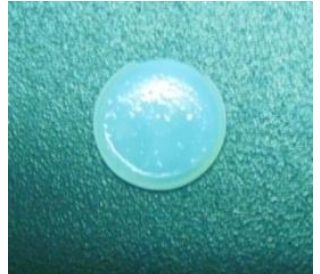

(b)
Figure 10: Images of $\mathrm{AgNO}_{3}$ doped glass sample (a) before and (b) after dropping $\mathrm{HCl}$ solution

Similarly, sodium chromate $\left(\mathrm{Na}_{2} \mathrm{CrO}_{4}\right)$ leakage can also be detected by using barium chloride $\left(\mathrm{BaCl}_{2}\right)$ doped transparent samples figure 11). The reaction is given by,

$$
\mathrm{Na}_{2} \mathrm{CrO}_{4}+\mathrm{BaCl}_{2} \rightarrow \mathrm{BaCrO}_{4}+2 \mathrm{NaCl}
$$

$\mathrm{Na}_{2} \mathrm{CrO}_{4}$ solution dropped on the transparent samples turns it opaque due to the presence of the barium chromate $\left(\mathrm{BaCrO}_{4}\right)$. The copper sulphate doped transparent sample is also found to exhibit this opaque property (figure 12) by the following reaction,

$$
\mathrm{Na}_{2} \mathrm{CrO}_{4}+\mathrm{CuSO}_{4} \rightarrow \mathrm{Na}_{2} \mathrm{SO}_{4}+\mathrm{CuCrO}_{4}
$$

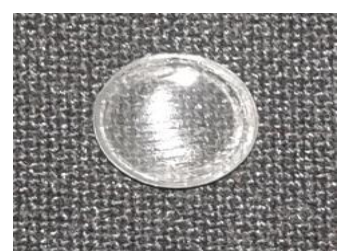

(a)

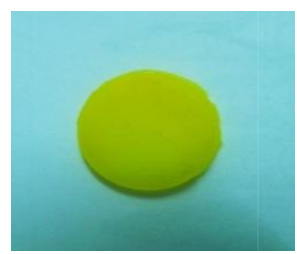

(b)
Figure 11: Images of $\mathrm{BaCl}_{2}$ doped glass sample (a) before and (b) after dropping $\mathrm{Na}_{2} \mathrm{CrO}_{4}$ solution 
INTERNATIONAL JOURNAL OF INNOVATIVE RESEARCH IN ELECTRICAL, ELECTRONICS, INSTRUMENTATION AND CONTROL ENGINEERING Vol. 3, Issue 12, December 2015

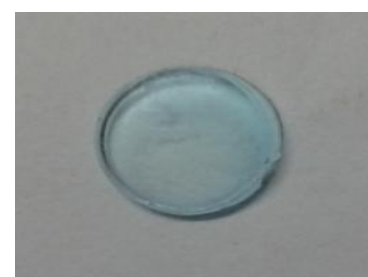

(a)

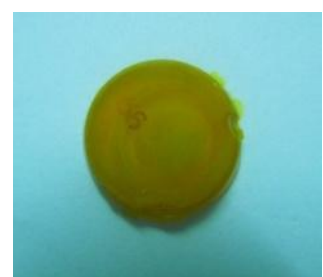

(b)
Figure 12: Images of $\mathrm{CuSO}_{4}$ doped glass sample (a) before and (b) after dropping $\mathrm{Na}_{2} \mathrm{CrO}_{4}$ solution

\section{Response time measurement:}

\begin{tabular}{|l|l|}
\hline Type of glass sample & Response time $(\mathrm{sec})$ \\
\hline $\mathrm{AgNO}_{3}$ doped & $1.0-3.0$ \\
\hline $\mathrm{BaCl}_{2}$ doped & $2.0-3.0$ \\
\hline $\mathrm{CuSO}_{4}$ doped & $3.0-4.0$ \\
\hline
\end{tabular}

Table 8: Estimation of response time for the glasses

Since the response time of these glass samples (table 8) are very short the sensor is highly sensitive to the leakage of $\mathrm{HCl}$ and $\mathrm{Na}_{2} \mathrm{CrO}_{4}$ solutions.

We found that the leakage of hydrochloric acid and sodium chromate solutions can be determined using solgel technique. The set up can be extended for sensing other chemicals in industries by doping the glass with suitable dopants. The thin films prepared using this technique find immense potential in sensing other chemicals using smart device.

\section{CONCLUSION}

The structural studies like FTIR spectrum analysis and porosity studies of glass samples were done to confirm the rigid glassy network and nanopore size of the sample. The indicators like methyl orange, phenolphthalein and universal indicator were incorporated in glass samples and its reversible characteristics were studied. Hence a solid$\mathrm{pH}$ sensor was proposed. Leakage of certain industrial chemicals were identified and reported. And a practical working model was constructed.

\section{ACKNOWLEDGEMENT}

Authors would like to thank principal, Sacred Heart College Thevara for providing infrastructure facilities and Dr. Jose K. B, Associate Professor, Department of Chemistry for chemical preparations.

\section{REFERENCES}

1. Brinker C J and Scherer G W, Sol-Gel Science-The Physics and Chemistry of Sol-Gel Processing, Academic Press., London(1990).

2. Wong P., Methods in the Physics of Porous Media, Academic Press, London, 1999, pp. 17-38.

3. Steven S. Zumdahl (2009). Chemical Principles (6th ed.). New York: Houghton Mifflin Company. pp. 319-324.

4. Steven S. Zumdahl (2009). Chemical Principles (6th ed.). New York: Houghton Mifflin Company. pp. 319-324.

5. O. Lev, M. Tsionsky, L. Rabinovich, V. Glezer, S. Sampath, I. Pankratov, J. Gun, Anal. Chem. 67 (1995) 22A

6. D. Avnir, Acc. Chem. Res. 28 (1995) 328.

7. M.M. Collinson, A.R. Howells, Anal. Chem. 72 (2000) 702A.

8. M.M. Collinson, H.S. Nalwa (Editors ), Handbook of Advanced Electronic and Photonic Materials and Devices, Vol. 5, Academic Press, 2001, p. 163.
9. Camassel, Jean, and Patrick G Soukiassian. "Sensors Based on Interfaces." Journal of Physics D: Applied Physics J. Phys. D: Appl. Phys., 2007.

10. B.D. MacCraith, G. O'Keeffe, C. McDonagh and A.K. McEvoy, LED-based fibre optic oxygen sensor using sol-gel coating, Electron. Lett., 30 (1994) 888.

11. Ph.d Thesis, Structural and spectroscopic characterization of $\mathrm{ZnSe} / \mathrm{Eu} 3+$ and CdTe/Sm3+ doped Sol-gel silica glasses-Siby Mathew-M.G.Unniversity, Kottayam (2008).

12. I. Siminiceanu, I. Lazau, Z. Ecsedi, L. Lupa, C. Burciag, Chem. Bull. "POLITEHNICA" Univ.(Timisoara), 53 (2008) 1. 